\title{
A new protocol for oxygen isotope analysis of authigenic and biogenic fine silica grains using laser-extraction technique
}

\author{
J. Crespin ${ }^{a, *}$, A. Alexandre ${ }^{\text {a }}$, C. Sonzogni ${ }^{\text {a }}$, F. Sylvestre ${ }^{\text {a,b }}$ \\ ${ }^{\text {a }}$ CEREGE, CNRS, Université Paul Cézanne Aix-Marseille III, Europôle de l'Arbois, BP 80, 13545, Aix en Provence Cedex 04, France \\ ${ }^{\mathrm{b}}$ Université d'Angers, UFR Sciences, EA2644, 2 boulevard Lavoisier, 49045 Angers Cedex 1, France
}

Received 11 June 2005; accepted 19 August 2005

Available online 23 November 2005

\begin{abstract}
We report here a $30 \mathrm{~W} \mathrm{CO}_{2}$ laser heating protocol for analyzing oxygen isotope composition $\left(\delta^{18} \mathrm{O}\right.$ in \%o vs. V-SMOW) of quartz and amorphous silica grains lower than 50 and $2 \mu \mathrm{m}$ with a good external precision $(1 \sigma<0.15 \%)$. This technique is used to investigate $\delta^{18} \mathrm{O}$ composition of macro-, micro- and crypto-crystalline quartz cements of quartzite levels occurring in a sand sequence from the South of France (Apt Series), after a physical separation of the quartz cements. $\delta^{18} \mathrm{O}$ data obtained from this technique are compared with $\delta^{18} \mathrm{O}$ data obtained from in situ ion microprobe analyses. This study also presents promising results on $\delta^{18} \mathrm{O}$ analysis of phytoliths obtained with the laser heating protocol $(1 \sigma<0.1 \%$ )
\end{abstract}

(C) 2005 Elsevier B.V. All rights reserved.

Keywords: Oxygen isotope analysis; Silica grain; Laser-extraction technique

\section{Introduction}

Infra-red laser-heated fluorination techniques are now commonly used for analyzing oxygen isotope composition $\left(\delta^{18} \mathrm{O}\right)$ of grains of silicate and oxide minerals (e.g. Sharp et al., 2002) in order to investigate mineral genesis and related paleo-environments (temperature and water source). However, loss of ejecta or necessity to use a binder have prevented the spread of laser-heated fluorination investigations on grain size fraction lower than 30-50 $\mu \mathrm{m}$ (Fouillac and Girard, 1996; Kirschner and Sharp, 1997). This size fraction, enclosing most of authigenic and biogenic silica particles, is still analyzed using the conventional fluorination method, which is more time consuming and

\footnotetext{
* Corresponding author.

E-mail address: alexandre@cerege.fr (A. Alexandre).
}

involves higher amount of material than laser-heated fluorination techniques.

We report here a $30 \mathrm{~W} \mathrm{CO}_{2}$ laser heating protocol that leads to good external precision of $\delta^{18} \mathrm{O}$ analyses of quartz and opal size fractions lower than 50 and $2 \mu \mathrm{m}$.

This technique is used to investigate $\delta^{18} \mathrm{O}$ composition of macro-, micro- (with a structure made of crystals large enough to be distinguished under the optical microscope) and crypto-crystalline quartz (with a structure made of crystals too small to be distinguished under optical microscope). These quartz are physically separated (Alexandre et al., 2004) from cements of quartzite levels occurring in a sand sequence from the South of France (Apt Series) (Basile-Doelsch et al., 2005). $\delta^{18} \mathrm{O}$ data obtained from this technique are compared with $\delta^{18} \mathrm{O}$ data obtained from in situ ion microprobe analyses (SIMS, CRPG, Nancy, France; external reproductibility of $\pm 0.3 \%$ ) . 
Investigating $\delta^{18} \mathrm{O}$ of biogenic silica particles from soils, buried soils and continental sediments also give indications on terrestrial water cycle and temperature. Laser heating of biogenic silica particles has never been reported up to now. This study also presents first results on laser heating and $\delta^{18} \mathrm{O}$ analysis of phytoliths, which contain exchangeable oxygen that makes necessary an equilibration procedure with water of known isotopic composition (Labeyrie and Juillet, 1982), prior to oxygen extraction. $\delta^{18} \mathrm{O}$ is expressed in \%o vs. V-SMOW.

\section{Results}

A new laser heating protocol for analyzing $\delta^{18} \mathrm{O}$ of silica powders $<50$ and $<2 \mu \mathrm{m}$ is presented below. Molecular $\mathrm{O}_{2}$ is extracted from quartz using a laser extraction technique close to the one described by Sharp (1990) and bulk oxygen isotope ratio is measured from $\mathrm{O}_{2}$ gas using a ThermoQuest Finnigan Delta Plus mass spectrometer at CEREGE (Aix en Provence, France). A Merchanteck $30 \mathrm{~W} \mathrm{CO}_{2}$ IR laser is used. Thirty-three samples of $1.5 \mathrm{mg}$ are loaded in a nickel sample holder, dried at $105{ }^{\circ} \mathrm{C}$ for $1 \mathrm{~h}$ and prefluorinated in a vacuum line for $1 \mathrm{~h}$. In an atmosphere of hundred millibars of $\mathrm{BrF}_{5}$, samples are preheated with a $0.1 \mathrm{~W}$ laser beam of $2000 \mu \mathrm{m}$ of diameter for $20 \mathrm{~s}$. The power of the $2000 \mu \mathrm{m}$ of diameter laser beam is then increased up to $12-13 \mathrm{~W}$ and samples are heated starting at the center and slowly moving the laser beam following concentric circles until a bowl of liquid silica forms. The laser beam is then focused to $1000 \mu \mathrm{m}$ and then to $200 \mu \mathrm{m}$ of diameter. Laser emission is stopped when all particles have disappeared. This protocol prevents ejectas. Replicate analyses of the international standard NBS $28(120-250 \mu \mathrm{m})$ give an average of $9.6 \pm 0.15 \%$ vs. V-SMOW. Replicate analyses of a laboratory quartz standard ("Boulangé") of 200/100, $100 / 50,50 / 2$ and $<2 \mu \mathrm{m}$ yield an average value of $16.46 \%$ vs. V-SMOW and an external precision of $0.15 \%$ o ( $\pm 1 \sigma ; 76$ analyses over 12 weeks), without any decreasing or increasing trend of $\delta^{18} \mathrm{O}$ averages with decreasing grain size (Fig. 1).

$\delta^{18} \mathrm{O}$ data obtained from cements of the quartzite levels from the South of France (Apt Series) using the ion microprobe show two groups of values: 1) Cements from samples S11, S4c and S14b have a similar $\delta^{18} \mathrm{O}$ composition averaging $26.45 \pm 0.71 \%$ o, whatever is the mineralogical phase. They form in upper quartzitic layers. This value is typical of authigenic quartz. 2) Crypto-quartz cements from samples $\mathrm{S} 5 \mathrm{~b}$ and $\mathrm{S} 13$ have similar $\delta^{18} \mathrm{O}$ values averaging $31 \%$. They form in lower quartzitic layers. This

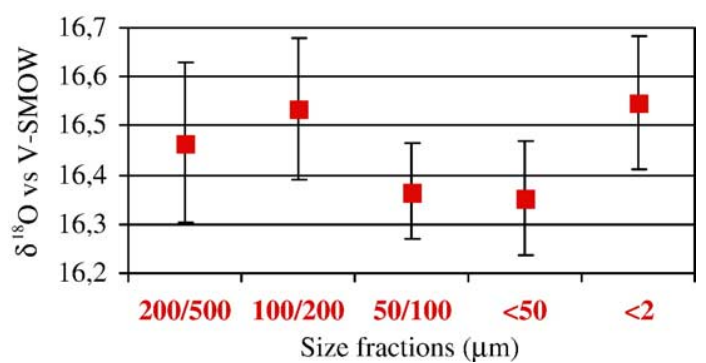

Fig. 1. Average $\delta^{18} \mathrm{O}$ values of several size fractions of the quartz lab standard "Boulangé" analyzed using Infra-red laser-heated fluorination technique. Average value: $16.46 \%$ vs. V-SMOW; Error bars give external precision calculated from replicate analyses: $\pm 0.15 \%$ o $( \pm 1 \sigma) ; 76$ analyses performed over 12 weeks. No $\delta^{18} \mathrm{O}$ trend with size is displayed which makes our laser heating protocol a success.

value is typical of shallow sea cherts (Sharp et al., 2002).

The comparison of $\delta^{18} \mathrm{O}$ data obtained by physical separation associated with the laser-heated fluorination technique, and by in situ ion microprobe analyses of the quartzite is presented in Table 1: 1) $\delta^{18} \mathrm{O}$ values measured on the $5-10 \mu \mathrm{m}, 2-5 \mu \mathrm{m}$ and $<2 \mu \mathrm{m}$ fractions of macro- or crypto-crystalline quartz by laser-fluorination are far lower than $\delta^{18} \mathrm{O}$ values measured in situ with the ion microprobe. 2) However, $\delta^{18} \mathrm{O}$ values measured on the $<2$ and $<1 \mu \mathrm{m}$ fraction of micro-crystalline quartz by laser-fluorination are similar to $\delta^{18} \mathrm{O}$ values measured in situ with the ion microprobe.

$\delta^{18} \mathrm{O}$ analysis of a phytolith lab standard with the laser-heated fluorination technique is presented, for the first time. The lab phytolith standard is extracted from a soil layer made of $95 \%$ of grass phytoliths that occurs in volcanic soils of La Reunion (France) (Meunier et al., 1999). External precision $(1 \sigma)$ of the $\delta^{18}$ O measurements including equilibration procedure, laser-heated fluorination and IRMS analysis of $\mathrm{O}_{2}$ average $\pm 0.1 \%$ o (30 analyses).

\section{Discussion and conclusions}

\subsection{Reliability of laser extraction for analyzing $\delta^{18} \mathrm{O}$ of microscopic fine silica grains}

The laser protocol reported here allows the analyses of the $\delta^{18} \mathrm{O}$ composition of silica grain fractions lower than $30,20,10,5$ and $2 \mu \mathrm{m}$ with a reproducibility better than $0.15 \%$, without any decreasing or increasing trend of $\delta^{18} \mathrm{O}$ averages with decreasing grain size. Thirtythree analyses of $1.5 \mathrm{mg}$ of fine powder are made over 4 days. Up to now, these size fractions were still processed using conventional analysis which is a lot more time consuming and requires a much higher amount of 
Table 1

Comparison of $\delta^{18} \mathrm{O}$ data obtained from physical separation associated with laser-heated fluorination technique, and in situ ion microprobe analyses of quartzite cements

\begin{tabular}{|c|c|c|c|c|c|c|c|c|c|c|}
\hline & \multicolumn{5}{|c|}{$\begin{array}{l}\text { In situ ion microprobe(ion beam of } 30 \mu \mathrm{m} \text { ) } \\
\text { CRPG (Nancy, France) }\end{array}$} & \multicolumn{5}{|c|}{$\begin{array}{l}\text { Laser fluorination of micrometric fractions CEREGE } \\
\text { (Aix en Provence, France) }\end{array}$} \\
\hline & Sample \# & $\begin{array}{l}\text { Type of } \\
\text { quartz }\end{array}$ & $\begin{array}{l}\delta^{18} \mathrm{O}(\% \circ \text { vs. } \\
\text { V-SMOW) }\end{array}$ & S.D. & $n$ & Sample \# & $\begin{array}{l}\text { Mineralogical composition } \\
\text { of the cement }\end{array}$ & $\begin{array}{l}\delta^{18} \mathrm{O}(\% \circ \mathrm{vs} . \\
\mathrm{V}-\mathrm{SMOW})\end{array}$ & S.D. & $n$ \\
\hline \multirow[t]{10}{*}{ Upper quartzite } & \multirow[t]{5}{*}{$\mathrm{S} 4 \mathrm{c}$} & \multirow[t]{2}{*}{ DQ } & \multirow[t]{2}{*}{13.38} & \multirow[t]{2}{*}{0.14} & \multirow[t]{2}{*}{13} & $\mathrm{~S} 4 \mathrm{c} 2-5 \mu \mathrm{m}$ & & 26.18 & 0.48 & 2 \\
\hline & & & & & & $\mathrm{S} 4 \mathrm{c}<2 \mu \mathrm{m}$ & $\mathrm{MQ}, \mu \mathrm{Q}$ & 27.2 & 0.20 & 2 \\
\hline & & $\mu \mathrm{Q}$ & 27.57 & 0.91 & 22 & $\mathrm{~S} 4 \mathrm{c}<1 \mu \mathrm{m}$ & $\mathrm{MQ}, \mu \mathrm{Q}$ & 26.88 & 0.17 & 3 \\
\hline & & MQ & 26.65 & 0.69 & 3 & & & & & \\
\hline & & DQ & 8.29 & 0.34 & 1 & & & & & \\
\hline & \multirow[t]{2}{*}{ S14b } & & & & & $\mathrm{S} 14 \mathrm{~b} 2-5 \mu \mathrm{m}$ & & 19.79 & 0.15 & 2 \\
\hline & & Ov. & 26.34 & 0.29 & 6 & $\mathrm{~S} 14 \mathrm{~b}<2 \mu \mathrm{m}$ & Ov., MQ & 20.19 & 0.16 & 4 \\
\hline & \multirow[t]{3}{*}{11} & DQ & 10.84 & 1.90 & 6 & $\mathrm{~S} 11 \quad 2-5 \mu \mathrm{m}$ & & 24.35 & & \\
\hline & & $\mu \mathrm{Q}$ & 25.80 & 1.14 & 10 & $\mathrm{~S} 11<2 \mu \mathrm{m}$ & Ov., MQ., $\mu \mathrm{Q}$ & 25.80 & 0.01 & 2 \\
\hline & & MQ (crack) & 25.91 & 0.75 & 5 & & & & & \\
\hline \multirow[t]{4}{*}{ Lower quarzites } & \multirow[t]{2}{*}{$\mathrm{S} 13$} & DQ & 10.02 & 1.69 & 5 & & & & & \\
\hline & & CQ & 31.09 & 2.60 & 9 & $\mathrm{~S} 13<2 \mu \mathrm{m}$ & CQ & 22.05 & 0.19 & 2 \\
\hline & \multirow[t]{2}{*}{$\mathrm{S} 5 \mathrm{~b}$} & DQ & 10.48 & 1.62 & 4 & & & & & \\
\hline & & CQ & 30.99 & 0.54 & 7 & & & & & \\
\hline Sandstone & $\mathrm{S} 14 \mathrm{a}$ & DQ & 11.46 & 2.36 & 20 & & & & & \\
\hline
\end{tabular}

MQ: macro-crystalline quartz (made of individual crystals distinguishable with the naked eye); $\mu$ Q: micro-crystalline quartz (made of crystals large enough to be distinguished under the optical microscope); CQ: crypto-crystalline quartz (made of crystals too small to be distinguished under the optical microscope); Ov: overgrowth. Physical separation of micro-crystalline quartz is successful although other quartz phases are not correctly separated.

material $(10 \mathrm{mg})$. To overcome these methodological problems brings a significant improvement to the analysis of $\delta^{18} \mathrm{O}$ value of microscopic fine silica grains common in chert, quartzite, silicrete, weathering profiles and among biogenic silica particles.

\subsection{Efficiency of physical concentration of macro-, micro- and crypto-crystalline quartz size fractions}

Comparison of $\delta^{18} \mathrm{O}$ data obtained by size fraction separation associated with laser fluorination technique and from in situ microprobe analyses show that:

1) Fractions higher than 2 and $1 \mu \mathrm{m}$ give under-estimated $\delta^{18} \mathrm{O}$ values. This under-estimation indicates a mixture between detrital quartz $\left(\delta^{18} \mathrm{O}\right.$ values ranging from $6.4 \%$ to $20 \%$, Garlick and Epstein, 1967; Savin and Epstein, 1970; Clayton et al., 1972; Eslinger et al., 1973; Blatt, 1986; Graham et al., 1996) and authigenic quartz $\left(\delta^{18} \mathrm{O}\right.$ values ranging from 20\%o to 32\%o, Savin and Epstein, 1970; Graham et al., 1996; Kolodony and Epstein, 1976; Bird et al., 1992; Abdel-Wahab et al., 1998; Webb and Golding, 1998; Alexandre et al., 2004).

2) When the cement sample contains crypto-quartz only, $\delta^{18} \mathrm{O}$ values of the $<2 \mu \mathrm{m}$ fraction is also underestimated. Thus the separation method improperly concentrates crypto-crystalline quartz.
3) When cement samples include micro-crystalline quartz only, $\delta^{18} \mathrm{O}$ values of the $<2$ and $1 \mu \mathrm{m}$ fractions are similar to $\delta^{18} \mathrm{O}$ values obtained for the cement. Thus micro-crystalline quartz appear to be efficiently concentrated in the $<2 \mu \mathrm{m}$ fraction. Finally, the separation technique must be improved or applied to cement made of micro-crystalline quartz only, unless a $\delta^{18} \mathrm{O}$ plateau is displayed when analyzing decreasing size fractions.

Implications of the $\delta^{18} \mathrm{O}$ results presented above in term of cement genesis and paleo-environmental reconstruction were discussed previously (Alexandre et al., 2005).

\subsection{Reliability of laser extraction for investigating $\delta^{18} \mathrm{O}$ composition of phytoliths}

External precision using the laser-extraction technique for analyzing phytoliths $(1 \sigma<0.1 \%$ ) is better than external precision published up to now for diatom and phytolith analyses using the conventional method (e.g. Shahack-Gross et al., 1996; Schmidt et al., 2001; Webb and Longstaffe, 2000: $1 \sigma \pm 0.2 \%$ or $0.3 \%$ ). This technique also allows small amounts of material to be analyzed faster than with the conventional method. Thus, the laser-heated fluorination technique is very promising for investigating $\delta^{18} \mathrm{O}$ compositions of modern and fos- 
sil biogenic siliceous particles such as phytoliths, diatoms or sponge spicules, in a paleo-climatic reconstruction perspective.

\section{Aknowledgements}

Thanks to $\mathrm{M}$. Champenois and C. Rollion-bard (CRPG, Nancy, France) for the SIMS $\delta^{18} \mathrm{O}$ analyses, supported by UMR 161 IRD-CEREGE-LSTUR. Laser heating $\delta^{18} \mathrm{O}$ analysis (CEREGE, Aix en Provence, France) was supported by CEREGE.

\section{References}

Abdel-Wahab, A., Salem, A.M.K., McBride, E.F., 1998. Quartz cement of meteoric origin in silcrete and nonsilcrete sandstones, Lower Carboniferous, Western Sinai, Egypt. Journal of African Earth Sciences 27-2, 277-290.

Alexandre, A., Meunier, J.D., Llorens, E., Hill, S.M., Savin, S.M., 2004. Methodological improvements for investigating silcrete formation: petrography, FT-IR and oxygen isotope ratio of silcrete quartz cement, Lake Eyre Basin (Australia). Chemical Geology $211,261-274$

Alexandre, A., Sonzogni, C., Sylvestre, F., Basile-Doelsh, I., Meunier, J.D., Colin, F., 2005. Oxygen Isotope Analyses of Fine Powders using Laser-Extraction Technique: Application to Sandstone and Silcrete Quartz Cement Analysis and Comparison with Oxygen Isotope Data Obtained from Ion Microprobe Analyses, EGU, Vienna, April 25th-29th.

Basile-Doelsch, I., Meunier, J.D., Parron, C., 2005. Another continental pool in the terrestrial silicon cycle. Nature 433, 399-402.

Bird, M.I., Longstaffe, F.J., Fyfe, W.S., Bildgen, P., 1992. Oxygenisotope systematics in a multiphase weathering system in Haiti. Geochimica et Cosmochimica Acta 56, 2831-2838.

Blatt, H., 1986. Oxygen isotopes and the origin of quartz. Journal of Sedimentary Petrology 57 (2), 373-377.

Clayton, R.N., O’Neil, J.R., Mayeda, T.K., 1972. Oxygen isotope exchange between quartz and water. Journal of Physical Research 77 (17), 3057-3067.

Eslinger, E., Mayer, L.M., Durst, T.L., Hower, J., Savin, S.M., 1973. An X-ray technique for distinguishing between detrital and secondary quartz in the fine-grained fraction of sedimentary rocks. Journal of Sedimentary Petrology 43 (2), 540-543.
Fouillac, A.M., Girard, J.P., 1996. Laser oxygen isotope analysis of silicate/oxide grain separates: evidence for grain size effect? Chemical Geology 130, 21-54.

Garlick, G.D., Epstein, S., 1967. Oxygen isotope ratios in coexisting minerals of regionally metamorphosed rocks. Geochimica et Cosmochimica Acta 31, 181-214.

Graham, C.M., Valley, J.W., Winter, B.L., 1996. Ion microprobe analysis of ${ }^{18} \mathrm{O} /{ }^{16} \mathrm{O}$ in authigenic and detrital quartz in the St. Peter Sandstone, Michigan Basin and Wisconsin Arch, USA: contrasting diagenetic histories. Geochimica et Cosmochimica Acta 60-24, 5101-5116.

Kirschner, D.L., Sharp, Z.D., 1997. Oxygen isotope analyses of finegrained minerals and rocks using the laser-extraction technique. Chemical Geology 137, 109-115.

Kolodony, Y., Epstein, S., 1976. Stable isotope geochemistry of deep sea cherts. Geochimica et Cosmochimica Acta 40, 1195-1209.

Labeyrie, L., Juillet, A., 1982. Oxygen isotopic exchageability of diatom valve silica; interpretation and consequences for paleoclimatic studies. Geochimica et Cosmochimica Acta 46, 967-975.

Meunier, J.D., Colin, F., Alarcon, C., 1999. Biogenic silica storage in soils. Geology 27, 835-838.

Savin, S.M., Epstein, S., 1970. The oxygen isotopic compositions of coarse grained sedimentary rocks and minerals. Geochimica et Cosmochimica Acta 34, 323-329.

Schmidt, M., Botz, R., Rickert, D., Bohrmann, G., Hall, S.R., Mann, S., 2001. Oxygen isotopes of marine diatoms and relations to opal-A maturation. Geochimica et Cosmochimica Acta 65 (2), $201-211$.

Shahack-Gross, R., Shemesh, A., Yakir, D., Weiner, S., 1996. Oxygen isotopic composition of opaline phytoliths: potential for terrestrial climatic reconstruction. Geochimica et Cosmochimica Acta 60, 3949-3953.

Sharp, Z.D., 1990. A laser-based microanalytica method for the in situ determination of oxygen isotope ratios of silicates and oxides. Geochimica et Cosmochimica Acta 54, 1353-1357.

Sharp, Z.D., Durakiewicz, T., Migaszewski, Z.M., Atudorei, V.N., 2002. Antiphase hydrogen and oxygen isotope periodicity in chert nodules. Geochimica et Cosmochimica Acta 66 (16), 2865-2873.

Webb, J.A., Golding, S.D., 1998. Geochemical mass-balance and oxygen-isotope constraints on silcrete formation and its paleoclimatic implications in Southern Australia. Journal of Sedimentary Research 68-5, 981-993.

Webb, E.A., Longstaffe, F.J., 2000. The oxygen compositions of silica phytoliths and plant water in grasses: implication for the study of paleoclimate. Geochimica et Cosmochimica Acta 64-5, 767-780. 